\title{
Kitsch: sobre la representación burguesa del sentimiento Un análisis a partir de las interpretaciones de Ernst Bloch, Siegfried Kracauer y Walter Benjamin
}

María Belforte ${ }^{1}$

\section{Resumen:}

El objetivo del presente artículo es el estudio de las interpretaciones del Kitsch en las obras de Ernst Bloch, Siegfried Kracauer y Walter Benjamin durante la República de Weimar y los primeros años del régimen nacionalsocialista. Se analizan también las críticas filosófico-políticas de estos autores a las representaciones burguesas del sentimiento en tanto elementos determinantes de la construcción ideológica burguesa.

Palabras clave: Kitsch; sentimientos; estética burguesa; surrealismo; racionalismo.

\section{Kitsch: on the Bourgeois Representation of Feelings} An Analy sis according to the interpretations of Ernst Bloch, Siegfried Kracauer and Walter Benjamin

\begin{abstract}
:
This article aims at studying the interpretations of kitsch according to the readings of Ernst Bloch, Siegfried Kracauer and Walter Benjamin during the Weimar Republic and the rise of National Socialism. Their philosophical and political criticism to the bourgeois representation of feelings is here analyzed as a fundamental component of the bourgeois ideological construction.
\end{abstract}

Key words: kitsch; feelings; bourgeois aesthetics; surrealism; rationalism.

\section{Introducción}

Si los debates sobre el Kitsch fueron especialmente relevantes en el ámbito del pensamiento alemán a partir de la década de 1920, no resulta de este hecho, sin embargo, una definición consensuada del concepto en cuestión. Los análisis del Kitsch, extensamente elaborados en el ámbito de

1 Doctora en filosofía por la Universidad de Buenos Aires (UBA/Conicet). E-mail: mariabelforte@yahoo.com. 
la estética y la teoría del arte durante la República de Weimar, permiten no obstante mostrar, como resultado de las distintas posiciones, el vínculo esencial entre estética y política. Se abre, en el análisis del Kitsch, una dimensión histórica insoslayable: en tanto novedad estética, expresa un punto de inflexión en la conformación de las plasmaciones objetivas de la burguesía industrial de finales del siglo XIX.

El presente estudio se propone mostrar, a partir de los análisis de Ernst Bloch, Siegfried Kracauer y Walter Benjamin, que su compatibilidad subjetiva con el modelo antropológico burgués y su especificidad políticamente regresiva colocaron al Kitsch en un lugar de complementación con la ideología racionalista propugnada por el liberalismo.

Al referirse a la modernización de la sociedad industrial, Dieter Kliche señala tres rasgos estructurales del objeto kitsch: 1) inadecuación, heterogeneidad, disfuncionalidad; 2) acumulación, exceso de acumulación, sinestesia; 3) mediocridad y confort (KLICHE, 2001, pp. 276-7). En términos más generales su artículo sostiene:

El concepto hoy internacional de Kitsch se caracteriza por dos rasgos destacados: puede ser relacionado, por un lado, con todas las áreas del comportamiento estético, de las artes y de la vida, por lo que existen grandes dificultades para captar la estructura conceptual, los rasgos estructurales o incluso las cualidades de estilo del Kitsch; por otro lado, tiene el significado evaluativo unívoco de una calificación estética negativa. (KLICHE, 2001,p. 273) ${ }^{2}$

En su artículo de 1935 sobre el Kitsch, Norbert Elias establece sociohistóricamente la distinción definitiva que marca un corte en el arte y las formas de la burguesía capitalista industrial del siglo XIX y el mundo anterior del siglo XVIII, último siglo que tuvo un “estilo". Más allá de la vaguedad del término, que en su análisis de los años 30 Elias subraya y que aún permanece, su estudio propone un marco histórico que permite definir lo Kitsch como objeto de reflexión: se trata de una "cualidad figurativa muy peculiar" dada en la "inseguridad formal" inherente a las creaciones estéticas de la sociedad industrial (ELIAS, 1998, p. 62). Elias sugiere un probable origen del término a partir del vocablo inglés "sketch" y su vínculo con el verbo alemán "verkitschen"3. En este origen estaría plasmada la paradoja y la tensión inevitables del Kitsch, su doble vinculación: a los especialistas y a su gusto desarrollado, por una parte, y al consumo del público de la sociedad de masas, por otra.

2 Cuando no se indica algo diferente, se trata de una traducción propia.

3 Elias explica que en el medio de los especialistas de arte muniqueses, de lo destinado a la venta se decía que estaba "hecho para el verkitschen" (ELIAS, 1998, p. 71). Cabe recordar aquí la acepción del verbo alemán vinculada a la idea de vender algo barato. 
La hipótesis de lectura aquí propuesta es que el Kitsch expresa, en el contexto histórico-político alemán, una alternativa ideológica frente al völkisch, al J ugendstil y al anticapitalismo romántico de la República de Weimar. En la medida en que los elementos románticos se fueron debilitando, el Kitsch, afín a la cultura masiva de los empleados en las grandes ciudades, logra prevalecer con el devenir histórico debido a su afinidad con el racionalismo capitalista: consigue la incorporación del sentimiento como ausencia.

En las décadas del 20 y del 30, Bloch, Kracauer y Benjamin recuperan la noción de Kitsch desde una perspectiva filosófico-política. La peculiar característica del Kitsch, que Elias señala, hace de un fenómeno estético un ejemplo paradigmático para el estudio del vínculo inseparable entre las expresiones culturales y la estructura político-social en la que aparecen. En el presente estudio se analizará, en primer lugar, cómo Bloch inserta el Kitsch en su teoría de la asincronía [Ungleichzeitigkeit] para analizar el nacionalsocialismo, en segundo lugar se retomarán las reflexiones kracauerianas acerca del Kitsch y su vínculo con los sentimientos, y finalmente se recuperará la visión benjaminiana del Kitsch y su relación con los sueños.

\section{Burguesía polvorienta: el Kitsch y el enriquecimiento interior según la lectura blochiana}

El Kitsch posee para Bloch, hacia finales de la República de Weimar, afinidad con las clases medias. En el período de ascenso del nacionalsocialismo, Bloch escribe un artículo titulado Poesie im Hohlraum (1931) en el que detalla los elementos que constituyen los puntos nodales que unen a la clase media con la literatura kitsch:

Una cabeza que trabaja, que intuye lo que dice, difícilmente arribará aquí. En un estrato que vive de engañarse y de dejarse engañar, que desea el Kitsch y la fraseología más que ninguna otra cosa. (...) El lector pequeñoburgués exige el Kitsch, por el que se ve inmediatamente engañado. (BLOCH, 1965, p. 120)

En su artículo, Bloch deja claro que el ámbito de la poesía es inescindible de la ideología en la que se inscribe:

[El plus poético] nace de la agitación y fuerza de ensoñación insipientes de un individuo en sí "dotado"; pero necesita, para compensarse plásticamente y a través de ello para existir, un estrato social que lo reciba y cuyos contenidos y objetos en general son "espiritualmente" reflejables. (BLOCH, 1965, p. 118)

Pero Bloch realiza aquí una importante distinción en su análisis de clase, la alta burguesía no intenta disfrazar el interés económico brutal que la motiva: los tópicos neoidealistas y la moral decorativa son reemplazados 
por el empirismo y el positivismo. Su representación plástica encuentra su expresión por ejemplo en el racionalismo de una nueva objetividad (BLOCH, 1965, p. 123) ${ }^{4}$.

En su extenso análisis del nacionalsocialismo plasmado en Erbschaft dieser Zeit (Herencia de esta época), de 1935, Bloch introduce el tema del Kitsch en la primera sección del libro, titulada "Der Staub" (El polvo). La imagen del polvo se resume en el último fragmento que compone la sección, que bajo el nombre de "Haltlos" (Inestable) presenta parcialmente la hipótesis central del libro: existe un componente potencialmente liberador en el proceso político-ideológico de la burguesía devenida en fascista. El elemento irracional que, coetáneo de la brutalidad y la barbarie nacionalsocialista, pertenece sin embargo a un momento arcaico de la conciencia, se vincula también con lo utópico ${ }^{5}$. Bloch sugiere aquí metafóricamente la clave del libro, según la cual existe una coyuntura revolucionaria en la renovación de la vida a la que aspira la burguesía. Pero se trata de un viento que no sopla lo suficientemente fuerte: "Aquí el aire tal vez no es tan denso como antes. Pero aún no sopla, solo levanta polvo." (BLOCH, 1973, p. 28) El fragmento que lo precede lleva por título "Schreibender Kitsch"6 y define el sentido que el Kitsch posee en el libro:

Allí las cosas insípidas se encuentran fácilmente entre sí. [Lo insípido] escribe para la gente adormecida de la manera en que esta lo desea. El interior mismo de los lectores es aquí engañado, su exterioridad, que ellos perciben, no es aquella en la que ellos realmente están. (BLOCH, 1973, p. 28)

Bloch establece así un lazo estrecho entre el Kitsch y la mentira, a la que es condenado el escritor que no ha lidiado con ciertos sentimientos7. Con este vínculo, coloca al Kitsch en el ámbito de lo no racional e introduce el problema de la ensoñación y lo sensual en una interpretación históricopolítica. La constelación de imágenes a la que apela incluye los términos Schweinerei (cochinada), Versonnene (soñador), Knospentoll (maníaco por el florecimiento). En este ámbito, el heroísmo posible tan solo alcanza a levantar el polvo.

Esta lectura blochiana reconoce un uso del Kitsch por parte del nacionalsocialismo: se trata de la versión universitaria que lo "latiniza" y

\footnotetext{
4 Aunque Bloch analiza la expresión plástica de la "objetividad" [Sachlichkeit] en términos generales, también se refiere en ciertos casos a la corriente de la Nueva objetividad [Neue Sachlichkeit].

${ }^{5}$ Esta idea también se encuentra delineada en el ensayo anterior ya mencionado (BLOCH, 1965, p. 126).

6 Podría traducirse este título como "Kitsch literario", pero habría que advertir que en alemán el sentido elevado que refiere a la creación literaria se habría dado mediante el adjetivo literarisch.

7 Bloch se refiere aquí a los sentimientos como abgelegte Gefühle. Interpretamos estos sentimientos remotos, guardados, como aquellos pertenecientes a la Irratio, claves para la interpretación blochiana.
} 
que constituye un refinamiento del engaño de Hitler ${ }^{8}$. Aquí el análisis de Bloch se enmarca en una interpretación de la categoría de conciencia temporal en la que el concepto de Ungleichzeitigkeit posee un lugar central. La realidad del presente no constituye un todo homogéneo y sincrónico sino que se compone de elementos pasados que conviven e interpenetran el presente: "No todos se encuentran allí en el mismo ahora." (BLOCH, 1973, p. 104) ${ }^{9}$ Este componente heterogéneo de la realidad de la conciencia señala en dirección a lo pasado en un doble sentido: 1) el regresivo, que contiene el deseo de sometimiento del presente y 2) el utópico, ya que refiere a los deseos constantes pero no actualizados de un futuro pasado que no se ha hecho aún presente. Esta es la forma en que lee Bloch las potencialidades de lo no contemporáneo. El nacionalsocialismo logra esconder las contradicciones contemporáneas del capitalismo en el uso de imágenes arcaicas que, presentes en la conciencia colectiva alemana, enmascaran y disfrazan dichas contradicciones.

En el contexto de esta concepción histórico-temporal, el Kitsch forma parte para Bloch de lo que denomina Hieroglyphen des XIX. Jahrhunderts (J eroglíficos del siglo XIX): "La forma en que este siglo [XIX] soñó, plasmó retrospectivamente, mezcló y reemplazó épocas pasadas se condensa en un jeroglífico." (BLOCH, 1973, p. 381) El sueño de una transformación que se expresa en el grito de los burgueses del siglo XIX indica su concepción de la subjetividad: "Enriqueceos" (BLOCH, 1973, p. 381). Este aspecto subjetivo es para Bloch el que prevalece en la contradicción entre el modo social de producción industrial y la forma privada de apropiación capitalista, frente a la novedad de la ingeniería tecnológica. Esta última queda relegada frente a la decoración, a la "anarquía de estilos" que caracteriza al siglo XIX:

En Alemania, antes que nada, en vista de la nobleza políticamente persistente en la antigua ornamentación de este Reich, floreció el burgués gentilhomme 200 años después de Molière con insospechado esplendor; su inseguridad interior como su apariencia onírica histórica definieron tanto la sociedad como la cultura. Brevemente: si la mayoría de los hombres de entonces actuaban de manera sobria y burguesa, lo ocultaban o no encontraban una forma para ello. (BLOCH, 1973, pp. 382-3)

\footnotetext{
8 Bloch denuncia a las figuras intelectuales destacadas que apoyan el ascenso del movimiento nazi. El texto sostiene exactamente: 'Las eternamente iguales e ignorantes arias que Hitler les canta a sus pequeñoburgueses no se vuelven tampoco mejores cuando la prostituta universitaria que él encontró (como Guillermo II encontró la suya en 1914) latiniza el Kitsch y mejora el engaño con refinamientos a la Schmitt o Freyer o Heidegger." (BLOCH, 1973, p. 74)

9 Argumentativamente, el concepto de Ungleichzeitigkeit atraviesa los análisis del libro y es referido explícita e implícitamente reiteradas veces.
} 
La artificialidad que caracteriza al interior burgués continúa en el exterior, en la calle; los motivos del siglo son la inautenticidad [Unechtheit] y la apariencia onírica exuberante (BLOCH, 1973, p. 384). Incluso el arte de la época es entendido por Bloch como una fachada: "el arte de entonces consistió en un baile de máscaras" (BLOCH, 1973, p. 385). El Kitsch es en esta interpretación parte de la incapacidad de expresión de la subjetividad cuya individualidad carece de forma, el fortalecimiento de la interioridad se hace a costa y en contradicción con lo social:

Los burgueses, que se hicieron grandes de un día para el otro, no supieron cómo sostener esto, su Kitsch se volvió por lo tanto incluso mayor. No se debe olvidar aquí, sino observar ya al principio, que la voluntad de enriquecerse también ha dado a luz algo real. (BLOCH, 1973, p. 381)

La realidad creada por la voluntad de enriquecimiento del individuo, ese entrelazamiento de objetos y de estilos que se manifiesta en la vivienda burguesa, evidencia su decadencia en el siglo XX. Los sueños de acrecentamiento interior se mitifican al no encontrar su contraparte en lo social. Los análisis de Bloch se acercan aquí al estudio del interior que se lleva a cabo en el proyecto inconcluso de Benjamin sobre los pasajes parisinos.

\section{El Kitsch y los deseos primitivos en Kracauer: un análisis del sentimiento ausente}

Ya en una etapa temprana de su pensamiento, Kracauer alude al Kitsch como fenómeno vinculado a la resolución. El sentido que le otorga se encuentra cargado sin embargo de la atmósfera fuertemente mesiánica que permea sus escritos hasta mediados de la década del 20 aproximadamente. En efecto, en su ensayo sobre la novela policial, Kracauer coloca al Kitsch en el lugar de cierre. Este cierre posee un carácter negativo dado que crea una esfera de redención que no existe en el orden terrenal. Con ello se liga al Kitsch a una doble impronta que permanecerá luego en análisis posteriores: 1) su vínculo intrínseco con una irrealidad y 2) su exitoso carácter distorsivo. La posición adjudicada al Kitsch al finalizar el análisis sostiene que el sentimentalismo es constitutivo del Kitsch"10 y que este "encuentra una realización con la cual lo auténtico es meramente aludido" (SKW 1, pp. 207; 209). La construcción del final de la novela policial es para Kracauer sentimental debido a que "invoca una aspiración a los sentimientos correspondientes al de la reconciliación, sin otorgarles realidad" (SKW 1, p. 209).

10 Kracauer lo denomina allí un "ästhetisches Konstituens". 
Pocos años más tarde, Kracauer vincula nuevamente al Kitsch con este aspecto de la subjetividad relativo a los sentimientos. Así como las interpretaciones de Bloch subrayan el lado objetivo del Kitsch, su condicionamiento histórico, Kracauer hace referencia también a las condiciones subjetivas de recepción. Para Bloch, la peculiaridad material del Kitsch se encuentra dada en su condición de ser producto de la individualidad burguesa. La multiplicidad de formas que indican una falta de estilo y de representatividad de un sujeto encapsulado en su vida privada apelan a lo exótico y a la búsqueda de una identidad siempre pospuesta. Kracauer subraya hacia 1926 en Edelkitsch la funcionalidad del Kitsch en el polo opuesto del proceso dialéctico entre el sujeto y el objeto: el Kitsch devuelve al receptor la apariencia de un sentimiento y fija dicho sentimiento a una máscara que esconde una ausencia:

El árbol de navidad es un motivo kitsch especialmente resistente. Se convierte en un patrón vacío si uno hace de él un acontecimiento social, para una decoración que es justamente lo suficientemente buena para fotografiar. Es kitsch porque no proporciona sentimientos, sino simplemente su imagen. (...) $\mathrm{Si}$ el Kitsch por un lado desprecia lo real como nulidad, por otro lado confiere a la nada el rango de la realidad. Un baile de una película se representa: uno cree el champán en la copa, supone conversaciones que justifican la risa de caballeros y damas. Mas el champán burbujea tan poco como las conversaciones, es todo una fachada, como las pecheras y los encajes. Lo vacío se comporta como un algo y es también tal vez algo, cuando uno sabe sobre su vaciedad. (SKW 5.2, p. 402)

De esta conexión que Kracauer establece entre la ausencia, la vaciedad [Hohlheit], sobre la que se sostiene el Kitsch, llegará en 1927 a otra en la que establece una relación entre el Kitsch y la vida:

Pero ¿es la sociedad la que realmente se muestra en el colportage cinematográfico? Esas salvaciones sentimentales, esa nobleza imposible, esos jóvenes y pulidos gents, esos monstruosos estafadores, criminales y héroes, esas morales noches de amor que terminan en inmorales casamientos ¿existen realmente? Sí que existen: léanse los anuncios generales. No hay Kitsch que la vida misma no supere. Las muchachas de servicio no necesitan los epistolarios de amor, sino que, al contrario, son estos los que han sido compuestos según las cartas de las muchachas de servicio, y hay jóvenes que todavía se lanzan al agua cuando imaginan infiel a su novio. El colportage cinematográfico y la vida se corresponden habitualmente el uno a la otra porque las mecanógrafas se modelan según los modelos de la pantalla; tal vez los modelos más engañosos hayan sido robados de la vida. (KRACAUER, 2006, p. 232)

En este caso, el vínculo se establece con el concepto de vida. El fundamento está puesto allí para contraponer su verdad a la falsedad del 
Kitsch: como copia de la vida expresa, sin embargo, un modelo que otorga a su vez identidad y fundamento al vacío de la vida. Kracauer subraya esa relación dialéctica entre original y copia para mostrar la dinámica de la existencia desamparada: la escalada de vacío se potencia con cada modelo. La ficción de la vida se duplica en la ficción del sentimiento de la vida.

En este sentido, el Kitsch indica una conexión con lo más propio del ser humano. En el breve escrito de 1926, lo explica:

Las personas cultas se indignan siempre mucho respecto del Kitsch. Deberían hacerlo siempre con una salvedad solamente. Cada hombre tiene una inclinación al Kitsch, responda por eso o no, cada hombre tiene derecho al Kitsch. Uno no puede vivir siempre con todo el empleo de sus fuerzas y además: el Kitsch expresa cuán bárbaramente los deseos primitivos sensoriales y espirituales de los hombres permanecen. ¿Quién no sería feliz como un niño con la nobleza de espíritu de Winnetou? ¿Quién no se dejaría atrapar dubitativamente por la dulzura de una canción de éxito de una opereta que sabe como el chupetín de la feria? (SKW 5.2, p. 401)

El Kitsch muestra los deseos primitivos unidos a la vida del hombre. Este aspecto del Kitsch no puede, según Kracauer, simplemente ser negado. Lo que debe temerse es su inserción en el arte:

El Kitsch se vuelve preocupante solamente cuando se da artísticamente. Produce la apariencia para las masas acríticas, de que él pudiera satisfacer necesidades más altas. Este Kitsch noble se comporta anímicamente sin tener alma, y aparenta destinos que no son tales. Es una imitación para la cual la despreocupación del Kitsch manifiesto merece volverse anticipada de lejos. (SKW 5.2, p. 401.)

El sentido político de la literatura y del arte es subrayado en los análisis de Kracauer, sentido sobre el que insiste implícita y explícitamente en sus escritos ${ }^{11}$. En relación con este punto, el contenido falsificador del Kitsch posee implicancias que muestran su función ideológica de tergiversar la realidad. Los análisis de Kracauer, de esta manera, ponen el acento en ese aspecto que Bloch distingue en la afinidad de las capas medias con el Kitsch.

Pero esta interpretación del Kitsch se encuentra alejada de su lectura del ornamento. Esta se enmarca también en una interpretación más abarcativa del desenvolvimiento de las estructuras racionales de la primera posguerra. Se trata de su análisis del ornamento como "reflejo estético de la racionalidad anhelada por el sistema económico dominante" (KRACAUER, 2008, p. 56):

${ }^{11}$ En relación con el sentido de la literatura, cf. por ejemplo el reportaje publicado en Monde en 1929 (SKW 5.3, pp. 137-44). El fin que allí destaca para la literatura consiste en "destrozar [zerstören] la ideología del régimen dominante" pero, afirma allí, también la dela oposición superficial dependiente de ella (SKW 5.3, p. 141). 
Si el ornamento de masas es considerado desde la perspectiva de la razón, entonces se revela como el culto mitológico que se oculta en una vestidura abstracta. (...) En realidad el ornamento es la crasa manifestación de la naturaleza inferior. Se puede mover tanto más libremente cuanto más decididamente la ratio capitalista se separa de la razón y, haciendo caso omiso del hombre, se volatiliza en el vacío de lo abstracto. (KRACAUER, 2008, p. 62)

Así, el ornamento de las masas se diferencia del adorno kitsch. Este último evoca un sentimiento, no una abstracción ${ }^{12}$. En ambos casos se cae en el ámbito de lo mitológico.

\section{El Kitsch como manifestación onírica en la lectura de Walter Benjamin}

Con la vinculación del Kitsch a los sueños, la lectura benjaminiana lo acerca al surrealismo. En la segunda mitad de la década del 20 esta mirada implicaba para Benjamin encontrarle una potencialidad revolucionaria: "El lado que la cosa vuelve en dirección al sueño es el Kitsch." (GS II/2, p. 620) El Kitsch es ese aspecto del objeto que hace entrar en el ámbito del sueño y, por lo tanto, se presenta como jeroglífico a ser descifrado:

Hace tiempo que el psicoanálisis descubrió los jeroglíficos como esquematismos de la labor onírica. Sin embargo, con esta certeza seguimos nosotros, más que la huella del alma, la de las cosas. Buscamos el árbol totémico de los objetos en la espesura de la prehistoria. La suprema y última caricatura de este árbol totémico es el Kitsch. (BENJ AMIN, 2005, p. 231)

El Kitsch es interpretado por Benjamin como un producto que entra en contacto con las masas y que por ello involucra el sentido del tacto y la corporalidad. Se encuentra en oposición al arte y al aura de lejanía en la que predomina lo visual. Las esperanzas de Benjamin, en algunos escritos, están puestas en la apropiación que el cine pueda hacer de esta nueva forma de involucramiento perceptivo en el que el aura deja lugar al contacto y a la cercanía, abriéndole paso a su función política. En este contexto, el Kitsch "no es sino arte con un carácter de uso, absoluto y momentáneo, del cien por cien" (BENJ AMIN, 2005, p. 401).

Kambas indica el hecho de que según esta lectura "el Kitsch, en tanto fenómeno de crisis, puede provocar una purificación de la percepción" (KAMBAS, 2014, p. 870). Este optimismo acompaña la

12 Por otra parte, para Kracauer, el portador del ornamento es la masa. A diferencia del Kitsch, ligado a la producción industrial, el ornamento posee una íntima vinculación con lo corporal y lo orgánico (cf. SWK 5.2, pp. 612 ss). 
interpretación de las posibilidades técnicas de su famoso ensayo sobre la obra de arte y ciertas lecturas que aparecen esbozadas también en Das Passagen-Werk ${ }^{13}$. El Kitsch, como manifestación onírica de los sueños de la burguesía imperial, ofrece a las masas la posibilidad del contacto corporal en la cercanía.

Benjamin tenía claro, hacia mediados de la década del 30, que la transformación revolucionaria era imposible sin una crisis de los paradigmas perceptivos que elaboran los sueños, valores y deseos del colectivo. Y piensa esa transformación a través de las relaciones y las constelaciones oníricas que se trasmiten de manera generacional. Es por ello que a menudo se refiere a la generación de los padres, como lo hace en su breve Traumkitsch (Kitsch onírico): "Pues el sentimentalismo de nuestros padres, muchas veces destilado, es justamente bueno para establecer la imagen más objetiva de nuestro sentimiento." (GS II/2, p. 621) El sentimentalismo de los padres es un punto esencial para la comprensión de lo Kitsch en el contexto de análisis del pasaje de siglo que se extiende durante toda la década del 30 y su inicio coincide temporalmente con este breve ensayo.

En efecto, esquemas de trabajo elaborados hacia mediados de los años 30 muestran que Benjamin esbozó un análisis de su proyecto sobre los pasajes por medio de una estructura dialéctica de tesis, antítesis y síntesis. La síntesis, que denomina aquí "Doctrina del despertar", involucraba tres dialécticas: 1) la de la perspectiva, 2) la de la moda y 3) la del sentimentalismo (GS V/2, p. 1.216). El Kitsch posibilita la cercanía al mundo de las cosas [Dingwelt] en el que se encuentran materializados los sueños y deseos de la generación anterior. Benjamin se plantea aquí una arqueología de la sensibilidad que involucre el despertar del componente erótico latente en la materia y expresado en la yuxtaposición de imágenes transmitidas en las formas adquiridas en el proceso de industrialización. El desciframiento de los jeroglíficos de la producción industrial es una función del despertar de la conciencia en la que se hacen conscientes las formas de la sensibilidad y el sentimiento plasmadas en los objetos. Se trata asimismo de un proceso de redención y revuelta contra ese mundo, tal como lo plantea el surrealismo en la consigna que Benjamin retoma y repite en su ensayo de 1929: "Ganar las fuerzas de la embriaguez [Rausch] para la revolución.” (GS II/1, p. 307) ${ }^{14}$ Con esta máxima, Benjamin

${ }^{13}$ Aunque se retome aquí el sentido estético y político del Kitsch, evidentemente Benjamin no ignoraba las condiciones materiales de su producción, que consideraba importantes para su análisis. En una anotación escribe: "Kitsch. Su análisis económico. De qué modo aparecen en él la superproducción de mercancías y la mala conciencia de los productores." (BENJ AMIN, 2005, p. 858)

${ }^{14}$ Se encuentra Benjamin en este punto muy cerca de Bloch, cuando descubre en el mismo proceso el elemento potencial redentor capaz de generar la fuerza del despertar. La embriaguez [Rausch], tema compartido con Bloch en la experimentación con hachís, es 
propone una perspectiva política en competencia con la poderosa atracción de lo que los historiadores reconocieron como transformación de lo político durante la República de Weimar. Una peculiar manera de vivir lo común, lo público a través de las emociones y los sentimientos ${ }^{15}$. Esta puesta en práctica de la sensibilidad en la participación política es eficazmente llevada a cabo por la derecha radical tras la derrota de 1918. Que Benjamin pensara su doctrina del despertar como una tríada de momentos dialécticos que involucraban la percepción y el sentimiento implicaba un corte definitivo con la tradición positivista del conocimiento y un acercamiento a la antropología del joven Marx ${ }^{16}$. Con Sentimentalität se refiere a una forma de la sensibilidad burguesa que lo ocupa en sus años de estudiante y de pertenencia a la Jugendbewegung. El rechazo a la concepción amorosa y erótica de la generación de los padres tiene por ese entonces un lugar destacado en su pensamiento y permanece a lo largo del proceso de desenvolvimiento de su filosofía y el quiebre político de mediados de los años 20. Esta fidelidad crítica contra la sensibilidad burguesa se evidencia en su permanente búsqueda de una forma de la experiencia auténtica y absoluta ${ }^{17}$.

\section{Conclusiones}

Los análisis del Kitsch llevados a cabo por Bloch, Kracauer y Benjamin poseen un elemento común que los vincula y funciona como fundamento de sus reflexiones: el nudo del que parten sus críticas se sostiene en un eje estructural político. Se trata de una referencia común a la ausencia de vinculación humana real que se expresa en el Kitsch. En el Kitsch se manifiesta con gran evidencia la escisión del sentimiento del ámbito de lo común; el sentimiento, para el orden liberal, pertenece a la esfera de lo privado. En el marco de lo público se vuelve abstracto. De ello se deduce que la crítica estética resulta íntimamente afín a la crítica antropológica marxista. El vacío del sentimiento del Kitsch que diagnostica

un elemento central del estudio sobre el nacionalsocialismo de este último. El componente irracional que el surrealismo pondría en juego políticamente había sido apropiado por la contrarrevolución del fascismo. El Kitsch es pensado desde esta misma potencialidad dual: "caricatura del árbol totémico", esto es, manifestación de lo arcaico por medio de las nuevas herramientas técnicas de producción.

15 Al estudiar la conformación de la ideología nacional alemana, el historiador Mosse denomina a este cambio "nueva política" (cf. MOSSE, 2005, cap. 1).

16 De hecho, Benjamin cita escritos tempranos de Marx reiteradas veces en Das PassagenWerk. Cf. por ejemplo el epígrafe del Konvolut N (GS V/ 1, p. 570).

${ }_{17}$ Una expresión acabada de esta búsqueda se encuentra en Einbahnstrasse, creación en la cual lo político en un sentido radicalmente antiburgués se entrelaza con lo erótico. 
Kracauer, y que Bloch liga a una forma de expresión de la Irratio ${ }^{18}$, posee su punto de referencia común en el resquebrajamiento del anclaje del sentimiento a un humanismo real. El Kitsch expresaría esa limitación del vínculo entre el sentimiento y aquello que el joven Marx llama "ser genérico". Se trata de una objetivación material de la forma de la alienación que en los Manuscritos económico-filosóficos se indica del siguiente modo:

\begin{abstract}
Una consecuencia inmediata de que al hombre le sea alienado el producto de su trabajo, de su actividad vital, de su ser genérico, es la alienación del hombre respecto del hombre. Si el hombre se enfrenta consigo mismo también se le enfrenta el otro hombre. (MARX, 2006, p. 114)
\end{abstract}

El Kitsch, en este sentido, moviliza el sentimiento sin vincularse al ser genérico. La fuerza de la Irratio queda limitada al ámbito de lo individual y de lo privado y de esta manera pierde su carácter de humanidad. De allí la enorme capacidad emotiva del Kitsch y su tendencia a desvincularse de un sentido humano universal. "La proposición según la cual el ser humano se ve alienado de su ser genérico significa, simplemente, que un hombre se ve alienado de otro, así como cada uno de ellos se ve alienado de la esencia humana." (MARX, 2006, p. 114)

Se ve así la compatibilidad subjetiva del Kitsch con el modelo antropológico burgués; su tendencia políticamente regresiva coloca fácilmente al Kitsch en un lugar de complementación con la ideología racionalista propugnada por el liberalismo. La emotividad permanece en el ámbito de lo individual, de lo privado, y el sentimiento humano común resulta vacío.

Según esta lectura, que estaría alejada de la visión un tanto más optimista de Benjamin presente en su ensayo sobre la reproducibilidad de la obra de arte, el vínculo del Kitsch con las masas, su capacidad de ser consumido, es una consecuencia o un aspecto sociológico secundario y no constituye su esencia. El punto central que lo distingue en cambio es su capacidad de generar un falso sentido de vinculación, de realidad, en el que se apela a un sentimiento humano que se encuentra ausente. Desde el punto de vista de un humanismo real, el problema del Kitsch no es su masividad, sino su función distorsionadora en la representación y reproducción de los sentimientos.

Pero la exteriorización de esa ausencia es ya una forma de revelación. Kracauer, al analizar la decadencia de los pasajes, señaló la desnudez con que las producciones capitalistas se mostraban:

18 El concepto de "Irratio" es utilizado por Bloch en las argumentaciones de Erbschaft dieser Zeit, en donde subraya la importancia de ocuparse de su crítica (cf. BLOCH, 1973, pp. $16 \mathrm{ss})$. 
Lo que unía a los objetos en el Pasaje de los Tilos y les impartía a todos la misma función era su repliegue de la fachada burguesa. (...) Cuando era posible eran ejecutados y si no podían ser completamente destruidos eran apartados y desterrados a la Siberia interior del pasaje. Aquí sin embargo se vengaban del idealismo burgués que los oprimía poniendo en juego su existencia profanada contra la pretendida por el idealismo. Denigrados como estaban lograban reunirse en la media luz del pasaje y organizar afuera una protesta efectiva contra la cultura de la fachada. Ponían al desnudo el idealismo como lo que era y desenmascaraban sus productos como Kitsch. (SKW 5.3, p. 398)

En 1931, Bloch analiza el presente de la poesía alemana y muestra un desdoblamiento del antiguo ideal de reconciliación que se observaba, con mayor o menor profundidad y con características diferentes, en la filosofía del siglo XVIII y comienzos del siglo XIX. Pero en el siglo XX, diagnostica Bloch, "no es posible ya tener una reconciliación con este mundo" (BLOCH, 1965, p. 125). El Kitsch es resultado de esa escisión que derivó en un reforzamiento de los elementos de expresión ideológicos.

En el contexto de un análisis histónico-político, los estudios de Bloch, Kracauer y Benjamin destacan la capacidad evocativa del Kitsch y su especial función y vinculación con el sentimiento. En esta interpretación, el Kitsch no es analizado solamente como forma estética, sino como manifestación política que expresa la ausencia de un humanismo real. Este ha sido un punto determinante para su supervivencia tras la desaparición de la burguesía decimonónica que le dio origen.

\section{Referencias bibliográficas}

BENJ AMIN, Walter. Gesammelte Schriften [=GS] (ed. R. Tiedemann y H. Schweppenhäuser). Frankfurt / M: Suhrkamp, 1979-1989. 7 t.

. Libro de los pasajes. Trad. Luis Fernández Castañeda, Isidro Herrera y Fernando Guerrero. Madrid: Akal, 2005.

BLOCH, Ernst. Literarische Aufsätze. Frankfurt / M: Suhrkamp, 1965. . Erbschaft dieser Zeit. Frankfurt a/ M: Suhrkamp, 1973.

ELIAS, Norbert. "Estilo kitsch y época kitsch". Trad. Lisímaco Parra. En: WEILER, Vera (Comp.). La civilización de los padres y otros ensayos. Bogotá: Norma, 1998.

KAMBAS, Chryssoula. "Obra de arte”. Trad. de Martín Koval. En: OPITZ, M.; WIZISLA, E. (Comp.). Conceptos de Walter Benjamin. Buenos Aires: Las Cuarenta, 2014, pp. 845-86.

KLICHE, Dieter. "Kitsch". En: BARCK, Karlheinz; FONTIUS, Martin; SCHLENSTEDT, Dieter et al. (Ed.). Âsthetische Grundbegriffe. Ein 
Historisches Wörterbuch in sieben Bänden t. 3. Stuttgart/Weimar: Metzler, 2001, pp. 272-88.

KRACAUER, Siegfried. Werke [= SKW] (ed. I. Mülder-Bach e I. Belke). Frankfurt / M: Suhrkamp, 2004 ss. 9 t. . Estética sin territorio. Trad. de Vicente J arque. Murcia: Colegio de Aparejadores y Arquitectos Técnicos de Murcia, 2006. . La fotografía y otros ensayos. El ornamento de la masa 1. Trad. de Laura Carugati. Barcelona: Gedisa, 2008.

MARX, Karl. Manuscritos económico-filosóficos de 1844. Trad. y notas de Fernanda Aren, Silvina Rotembergy Miguel Vedda. Buenos Aires: Colihue, 2006.

MOSSE, George L. La nacionalización de las masas. Trad. de Jesús Cuéllar Menezo. Madrid: Marcial Pons, 2005.

Como citar:

BELFORT, María. Kitsch: sobre la representación burguesa del sentimiento. Un análisis a partir de las interpretaciones de Ernst Bloch, Siegfried Kracauer y Walter Benjamin. Verinotio - Revista on-line de Filosofia e Ciências Humanas, Rio das Ostras, v. 24, n. 2, pp. 147-160, nov. 2018.

Data de envio: 25 abr. 2018

Data de aceite: 22 jun. 2018 